\title{
Identification and Analysis of Plant Growth Promoting Bacteria in LEAF Community Garden Soil
}

\author{
Pooja Ramadas ${ }^{1}$, Dhruv Pathak ${ }^{2}$ and Prabhjeet Kaur" \\ 1'Dougherty Valley High School, San Ramon, CA, USA \\ ${ }^{2}$ Milpitas High School, Milpitas, CA, USA \\ \#Advisor
}

\section{$\underline{\text { ABSTRACT }}$}

In today's largely populated modern world, crop yield is becoming increasingly important. To increase crop yield, new modern technologies for farming are continuously being innovated. The aim of this study is the identification of Plant Growth Promoting Bacteria (PGPBs) and their properties. In order to conduct the experiment, soil samples were collected from the community garden LEAF (Local Ecology and Agriculture Fremont). These samples were grown in Luria Bertani agar plates, and the two bacterial strains that grew from them were analyzed to determine the species of the bacteria. Using a DNA extraction kit, DNA was extracted from the bacteria and then amplified versions were sent to RF Biotech for DNA sequencing. The DNA sequences were then used to determine that the two bacterial species in question are Bacillus cereus and Morganella morganii. Afterwards, multiple assays were used to measure the efficiency of each bacterial species to absorb various substances that would be helpful for plant growth. The aim of this research is to better understand which bacterial strains are beneficial for plants, and which are harmful. Through having greater zones of inhibition, the bacterial species $M$. morganii proved to be more efficient in the siderophore and phosphate solubilization assays. In contrast, the bacterial species B. cereus proved to be more efficient in the cellulase and amylase production assays. These results will assist LEAF in enriching their soil in order to increase their crop yields by creating an increase in concentration of advantageous bacteria and decrease that of detrimental bacteria.

\section{Introduction}

Plants use many different chemicals from soil that are usually unrefined. Bacteria help refine these chemicals so plants can use them more easily. These bacteria are known as plant growth promoting bacteria (PGPBs) and they enhance plant growth. A few examples of these are Rhizobium, Azospirillum, Pseudomonas, and Arthrobacter. These bacteria play many important roles, from protecting plants against disease to enhancing plant growth by purifying chemical compounds for better plant usage. ${ }^{1}$

They also have other jobs in which they produce compounds, such as nitrogen fixation, phosphate solubilization, and siderophore production. Phosphate solubilization, an integral part of plant health and an essential macronutrient in plants, is one such characteristic that was tested in this study. It involves the ability of bacteria to take phosphate compounds, which are often unusable to plants due to its inorganic form, and turn it into a soluble form that the plant can use. ${ }^{2,3}$ Siderophore production involves the synthesis of siderophores, which are molecules with low molecular mass and an affinity for binding iron, an essential micronutrient in plants. Another characteristic that implies that a PGPB is more effective is the use of enzymes, including cellulase and amylase. The enzyme cellulase works to decompose the compound cellulose. Additionally, the enzyme amylase is important for turning carbohydrates such as starch into sugar for a plant to use as energy. ${ }^{4}$

This study aims to better understand the microbiome of soil from LEAF, a local community garden based in Fremont. Through the isolation of individual bacteria strains and a series of assays, or tests, the present study aims to 
classify these bacteria as either beneficial, neutral, or detrimental for plant health and growth. These assays will be used to test various aforementioned plant growth promoting characteristics in PGPB, including phosphate solubilization, siderophore production, and the production of enzymes such as cellulase and amylase. Additional procedures, including DNA extraction, polymerase chain reaction (PCR), and DNA sequencing, will allow for the classification of the soil bacteria species.

Our study will aid LEAF in better understanding their soil fertility, allowing them to take further steps in enhancing its health and volumes of output. ${ }^{5}$ Such steps to promote soil virility include the introduction of new bacteria strains, promoting new sets of plant growth promoting traits, which may be lacking with the soil's current microbial composition.

\section{Methods}

After collecting a soil sample from LEAF community garden, a cultivation-dependent method of approach was chosen for studying the bacterial species.

\section{Serial Dilutions}

A 1 gram sample of soil from LEAF was weighed and added to $9 \mathrm{~mL}$ of deionized water in a collection tube. The mixture was vortexed for approximately 20 seconds, and $1 \mathrm{~mL}$ of the resulting suspension was transferred by micropipette to $9 \mathrm{~mL}$ of deionized water in another collection tube. This new collection tube was then vortexed again for 20 seconds. This dilution procedure was repeated an additional four times. Each time, $1 \mathrm{ml}$ of the previous mixture was transferred using a sterile micropipette into a collection tube with $9 \mathrm{~mL}$ of deionized water. The resulting collection tubes contained soil diluted from $10^{-1}$ to $10^{-6}$ grams of soil per mL. ${ }^{6}$

\section{Culturing and Purifying Isolated Species}

In order to grow the bacteria from the serial dilutions, Luria Bertani agar plates were created. First, $25 \mathrm{~g}$ of LB broth and $15 \mathrm{~g}$ of water were added to $1 \mathrm{~L}$ of water. This solution was stirred until the powder dissolved and the mixture became homogeneous. It was then autoclaved for 15 minutes at 15 PSI on a liquid cycle. Once the solution had been autoclaved, it was set at room temperature and allowed to cool down significantly. Three petri dish plates were labeled, and approximately $50 \mathrm{~mL}$ of LB agar was poured from the flask into each of the plates under a laminar flow hood. ${ }^{7}$ After approximately 10-15 minutes in the laminar flow hood, the agar had solidified and $10 \mathrm{~mL}$ of the last three serial dilutions were pipetted onto each of the three serial dilution plates. The soil dilutions were spread around their respective petri dish plates, and the plates were then sealed with parafilm. The plates were incubated at $30^{\circ} \mathrm{C}$ for approximately 4 days, allowing the bacterial colonies to grow. After four days, individual bacterial colonies from the serial dilution agar plates were inoculated onto new LB agar plates, isolating the various bacterial colonies. Further repetition of this process allowed for the bacterial strains to be fully isolated and purified. ${ }^{6}$

\section{DNA Extraction}

After completing all of the assays, the Zymo Research Quick-DNA Fungal/Bacterial Miniprep Kit was used to extract DNA from the bacterial colonies. The purpose of DNA extraction is to isolate the DNA from the bacterial colonies so that the DNA can then be analyzed using later procedures. The DNA extraction procedure was completed twice, for each of the two bacterial species that were isolated from the soil sample. 
To begin DNA extraction, 50-100 mg of bacterial cells are added along with $200 \mu \mathrm{l}$ of water and $750 \mu \mathrm{l}$ of buffer to the lysis tube. A bead beater fitted with a $2 \mathrm{ml}$ tube holder assembly is secured and then processed at maximum speed for approximately 5 minutes. The lysis tube is centrifuged in a microcentrifuge at $10,000 \times \mathrm{g}$ for $1 \mathrm{minute}$, and then $400 \mu \mathrm{l}$ of the resulting supernatant is transferred to a filter in a collection tube. This tube is then centrifuged at $8,000 \times \mathrm{g}$ for 1 minute, and $1200 \mu \mathrm{l}$ of Genomic Lysis Buffer is added afterward. At this point, $800 \mu \mathrm{l}$ of the resulting mixture is added to an IICR Column in a collection tube. This is centrifuged at $10,000 \times \mathrm{g}$ for 1 minute, the flow is discarded, and it is centrifuged again at $10,000 \times \mathrm{g}$ for 1 minute. Then, $200 \mu \mathrm{l}$ DNA Pre-Wash Buffer and $500 \mu \mathrm{g}-$ DNA Wash Buffer are added to the IICR Column in a new collection tube, and it is centrifuged at $10,000 \times \mathrm{g}$ for 1 minute after adding each buffer. The last step of DNA extraction is to transfer the IICR Column into a clean microcentrifuge tube and add 35 - $100 \mu$ of DNA Elution Buffer to the column matrix, and then centrifuge at $10,000 \times \mathrm{g}$ for 30 seconds to elute out the DNA. Approximately $0.1 \mathrm{~mL}$ to $0.2 \mathrm{~mL}$ of DNA was obtained for each of the two bacterial species. ${ }^{8}$

\section{Polymerase Chain Reaction}

After extracting the DNA from the two bacterial species, the polymerase chain reaction was completed. This was done to amplify the concentration of DNA, in order to make DNA sequencing easier. First, the resulting DNA samples from DNA extraction were transferred into mini eppendorf tubes. These tubes were placed into the PerkinElmer 480 DNA Thermal Cycler. The following thermal cycle was performed: $94^{\circ} \mathrm{C}$ for 3 minutes $(1 \mathrm{cycle}), 94^{\circ} \mathrm{C}$ for 1 minute, $55^{\circ} \mathrm{C}$ for 1 minute, $72^{\circ} \mathrm{C}$ for 2 minutes $\left(35\right.$ cycles), $72^{\circ} \mathrm{C}$ for 5 minutes ( 1 cycle) ${ }^{9}$

\section{DNA Sequencing}

Once DNA had been extracted out of each bacterial species and the DNA had been amplified through polymerase chain reaction, the DNA samples were sent to RF Biotech to be sequenced with Sanger sequencing. The primers used were $27 \mathrm{~F}$ and $1492 \mathrm{r}$, two types of $16 \mathrm{~S}$ universal primers. ${ }^{10}$ These primers measure approximately 1400 base pairs of DNA. After sequencing the DNA, RF Biotech sent back files containing the order of the nitrogenous bases in specific portions of the DNA. These sequences were then put into the Basic Local Alignment Search Tool (BLAST) on the National Center for Biotechnology Information (NCBI) website. The search was completed in the nucleotide collection database, and the results revealed the genus and species for each of the two bacterial strains. ${ }^{11}$

\section{Phosphate Solubilization}

This assay tests for how well the bacteria can use phosphate compounds and turn into a usable substance for plants. In order to make Pikovskaya's (PVK) agar medium, a flask was first filled with $250 \mathrm{ml}$ of DI water. Then 2.5 grams of dextrose, 0.125 grams of yeast, 1.25 grams of calcium phosphate, 0.125 grams of ammonium phosphate, 0.05 grams of potassium chloride, 0.025 grams of magnesium sulphate, and 0.000025 grams of ferrous sulphate and manganese sulfate were added to the $250 \mathrm{ml}$ of DI water. For the last 2 ingredients we used serial dilutions to get the desired concentrations. The resulting solution was stirred properly and autoclaved for 15 minutes. The final solution was poured into $100 \mathrm{ml}$ petri dishes and left to solidify for 5 minutes. Once solidified bacteria was taken from LB agar plates and inoculated onto the plates. This was left in an incubator for a week at 32 degrees celsius. ${ }^{12}$

Siderophore Solubilization 
This assay tests for how well a bacteria can use Iron (Fe). It requires hydrochloric acid, CAS(Chrome Azurol S), ferric chloride, HDTMA (hexadecyl trimethyl ammonium bromide), DI water, LB nutrient broth, and agar. First the glassware was rinsed. A flask was filled with $100 \mathrm{ml}$ of DI water. Then 0.012 grams of CAS solution, 0.27 grams of ferric chloride, and $0.821 \mathrm{ml}$ of $\mathrm{HCl}$ was added and dissolved. The HDTMA solution was 729 milligrams of HDTMA mixed in $400 \mathrm{ml}$ of distilled water. Then the solution was autoclaved alongside the CAS solution. Once that was done $10 \mathrm{ml}$ of the HDTMA solution was added to the $100 \mathrm{ml}$ solution of CAS and other ingredients. The final solution was poured into $100 \mathrm{ml}$ petri dishes. Each plate was split into halves and they had separate colonies of orange bacteria and white bacteria. Then this was incubated for 8 days in a 37 degree celsius incubator. ${ }^{13}$

\section{Cellulase Production}

This assay tests for how well the bacteria can use the enzyme cellulase. This procedure requires CMC (carboxymethylcellulose), monopotassium phosphate, magnesium sulfate, LB broth, and agar. A flash was filled with $250 \mathrm{ml}$ of DI water. 6.25 grams of LB Broth, 0.125 grams of monopotassium sulphate, 0.062 grams of magnesium sulfate, and 3.75 grams of agar were all added to the water and stirred. Once it was fully dissolved 0.062 grams of CMC was added and slightly heated. This allowed for the CMC to get more easily dissolved. Once all the chemicals were properly dissolved in the water we were able to autoclave it for 12 minutes. Once this was done the final solution was poured into plates and set to rest for 5 minutes. Once solidified, the bacteria were transferred from the LB agar plates and moved onto the CMC plates. This was then set in an incubator for 5 days. ${ }^{14}$

\section{Amylase Production}

This assay tests for how well the bacteria can use the enzyme amylase. The procedure requires Beef Extract (or HM Peptone B, which is equivalent to beef extract), soluble starch, and Agar. A flask containing $250 \mathrm{ml}$ of water was mixed with 0.75 grams of HM Peptone B, 2.5 grams of soluble starch, and 3.75 grams of agar. This was all dissolved together and then autoclaved for about 12 minutes. After autoclaving, it was taken out and then poured into $60 \mathrm{ml}$ Petri dishes. This was set to cool for about 20 minutes. Once the plates solidified, bacteria from aforementioned LB agar plates was placed onto the plates using inoculation tubes. The inoculated amylase agar plates were left to incubate for 6 days, and then the zones of inhibition were measured. ${ }^{15}$

\section{Results}

Everytime the size of the two bacterial species had greatly increased on their respective LB agar plates, the bacteria were inoculated onto new plates, providing them with more space and nutrients to continue growing. This resulted in bacterial strains that were more isolated and purified. This ensured that any procedures or assays completed with the bacteria derived accurate results. 


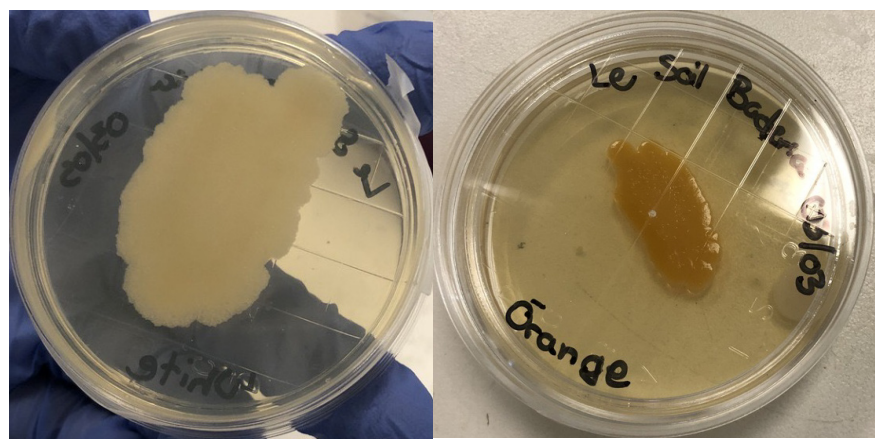

Figure A: White bacterial strain (on the left) and orange bacterial strain (on the right) that was isolated from the original serial dilution LB agar plates.

\section{DNA Sequencing}

Once DNA extraction, PCR, and DNA sequencing were completed on both of the isolated bacterial strains, the DNA sequences for each species was sent back from RF Biotech. The two sequences for each species are shown in Table A. Putting these sequences into the Basic Local Alignment Search Tool (BLAST) on the National Center for Biotechnology Information (NCBI) website showed that the species with a white phenotype was Morganella morganii and the species with an orange phenotype was Bacillus cereus. ${ }^{11}$

Table A: DNA sequences collected from RF Biotech. Each isolated strain had its DNA sequenced using two primers, $27 \mathrm{~F}$ and $1492 \mathrm{r}$.

\begin{tabular}{|c|c|c|}
\hline Strain & Primer & Sequence \\
\hline \multirow[t]{2}{*}{ White } & $27 \mathrm{~F}$ & $\begin{array}{l}\text { ATCGAGTGGCGGCTAAAATGCAGTCGGGCGGTAACAGGGAGAAGCTT- } \\
\text { GCTTCTCTGCTGAC- } \\
\text { GAGCGGCGGACGGGTGAGTAATGTATGGGGATCTGCCTGATGGAGGGGGATAACTACTGG } \\
\text { AAACGGTAGCTAATACCGCATAATGTCTTCGGACCAAAGCGGGGGAC- } \\
\text { CTTCGGGCCTCGCGCCATCAGATGAACCCATATGGGATTAGCTTGTAGGTGAGGTAACGG } \\
\text { CTCACCTAGGCGACGATCCCTAGCTGGTCTGAGAGGATGATCAGCCACACTGG- } \\
\text { GACTGAGA- } \\
\text { CACGGCCCAGACTCCTACGGGAGGCAGCAGTGGGGAATATTGCACAATGGGCGCAAGCCT } \\
\text { GACGCAGCCATGCCGCGTGTATGAAGAAGGCCTTCGGGTT- } \\
\text { GTAAAGTACTTTCAACCCCCCACGAAGGTGGCACCCCGCCTACCCTTATCTGTTGAGGGCC } \\
\text { GTCCCCCCCCCCCCCCCCCGCTGACCCCACCACCTAGAGGAGGCGCAA- } \\
\text { GCTGGTCTTCTGCCTGTGCCACCCCGTCC }\end{array}$ \\
\hline & $1492 \mathrm{r}$ & $\begin{array}{l}\text { GGACGTTACAGTGGTAGCGTCTCCGGAGGTAGCTACCTACTTCTTTTGCAACCCAC- } \\
\text { TCCCATGGTGTGACGGGCGGTGTGTACAAGGCCCGGGAACGTATTCACCGTAGCATTCTG } \\
\text { ATCTACGATTACTAGCGATTCCGACTTCATGGAGTCGAGTTGCAGACTCCAATCCGGAC- } \\
\text { TAC- } \\
\text { GACGTACTTTATGAGTTCCGCTTGCCCTCGCGGGGTCGCTTCCCTTTGTATACGCCATTGTA } \\
\text { GCACGTGTGTAGCCCTACTCGTAAGGGCCATGATGACTTGACGTCATCCCCAC- } \\
\text { CTTCCTCCGGTTTATCACCGGCAGTCTCCTTTGAGTTCCCGACATTACTCGCTGGCAACAAA } \\
\text { GGATAAGGGTTGCGCTCGTTGCGGGACTTAACCCAACATTTCACAACACGAGCTGAC- } \\
\text { GACAGCCATGCAGCACCTGTCTCAGAGTTCCCGAAGGCACCAATCCATCTCTGGAAAGTTC } \\
\text { TCTGGATGTCAAGAGTAGGTAAGGTTCTTCGCGTTGCATCGAATTAAAC- }\end{array}$ \\
\hline
\end{tabular}




\begin{tabular}{|c|c|c|}
\hline & & $\begin{array}{l}\text { CACATGCTCCAC- } \\
\text { CGCTTGTGCGGGCCCCCGTCAATTCATTTGAGTTTTAACCTTGCGGCCGCACTCCCCAGGC } \\
\text { GGACGGACTTAACGCGTTAGCTCCGGAAACCACGCCTCAAGGGCACTACCTCCAAGTTGA- } \\
\text { TATCGTTTACAGCGTGGACTACCAGGATATCTAATGGTGCCAGGCTCCTCAGGATTTCACA } \\
\text { CCAGAGCGACCAGTGTTATAGCCAGTTGGTCGACT }\end{array}$ \\
\hline \multirow{2}{*}{ Orange } & $27 \mathrm{~F}$ & $\begin{array}{l}\text { GGGGTGACCGCCAACAAAGACACTAGAAGAGAAGTCACCCTCGTGGGGGGTCGCAGGC- } \\
\text { TATTGGTGTGAGTGAAAGAAGGGGAGAAGAAAAATGGAAAGGAAAGACTGTAACCCATC } \\
\text { TCCGGGCCCCTGGCACATTCATCTCATCGTTATGACTGTTCCGCCCCCTTGTTGAC- } \\
\text { CTTCGCCCTTAGATTTTGGGACTTCACCTTTGTTATTAGATTCTACTGAGACTATCCTATAT } \\
\text { CGTGGAATGATTGTCCAATGTGAAACTATCACAACCTGGTTTCCTTTGCTTAC- } \\
\text { CGCCTTTCTGATGCAGATGGTGTCCTCGCATTTTATAATGTTGTATAGCCTGGATCTTGGTG } \\
\text { TTCGGCTGGCCCGATTGTATCTGCTTTCTGATGTACAGCATCCAGTTACCGGTCTGCAC- } \\
\text { CTACTCTCATTCTGGCCCGTGAATCCTCACTAGACGATGTGCCCAGCTTTATTTAGAGGCG } \\
\text { CTAATTTACCCC }\end{array}$ \\
\hline & $1492 \mathrm{r}$ & $\begin{array}{l}\text { TAATAATATTTATACAGTTTTAGTAGAGAAGTCTTATTACTAAGGAC- } \\
\text { GAAGGGAAAGGGAGGGAAAAGGTTAAAAGAAAGGAAAGAAGGTGAAAAAAAAGAAAAA } \\
\text { AAAGTTGATATTTCCACGTTTATGAAATTTTGGGCCCTGGCCCTCCTGAT- } \\
\text { TCGCCCTAGGTT- } \\
\text { GGGACCCCCGCCGGTCCAACTGCACCAGGGGTTACCCCCTTTTTGGGGAGGGTCCCATTGG } \\
\text { GCGCGCTTTTTATCCGGGCTAGCTACCCTTCTGTCGCGA- } \\
\text { TAGGCTCGCCCCCCCCCATGAAGGGGCACCTTTTTTTTTCGCCTCCGTTTTTAGCCTCTGTG } \\
\text { GGCCCCGCCCCTGAACCCTCATAGAGACCTCCCCCCCCCCGCTCCTATCTATAA- } \\
\text { TAGTGGGCGGGGT }\end{array}$ \\
\hline
\end{tabular}

Biochemical Assays

In the four biochemical assays that were used to test $M$. morganii and B. cereus, M. morganii proved to be more beneficial in two of the assays, while $B$. cereus proved to be more beneficial in the other two. In both the phosphate solubilization assay and the siderophore solubilization assay, M. morganii's zone of inhibition was more than twice that of B. cereus'. On the other hand, in the cellulase production assay, which used carboxymethylcellulose (CMC) agar plates, B. cereus had a zone of inhibition that was almost 3 times higher than the zone created by M. morganii. $B$. cereus also had a bigger zone of inhibition in the amylase production assay, with an average zone that was approximately $0.7 \mathrm{~mm}$ bigger than $M$. morganii's average zone.

Table B: Data collected on the sizes of the zones of inhibition from colonies of the two species in the phosphate solubilization assay.

\begin{tabular}{|l|l|}
\hline \multicolumn{2}{|l|}{ Phosphate Solubilization Assay - Zone of Inhibition } \\
\hline Species & Zone of Inhibition (mm) \\
\hline M. morganii & $20-30 \mathrm{~mm}$ in diameter (on average) \\
\hline B. cereus & $10 \mathrm{~mm}$ in diameter (on average) \\
\hline
\end{tabular}




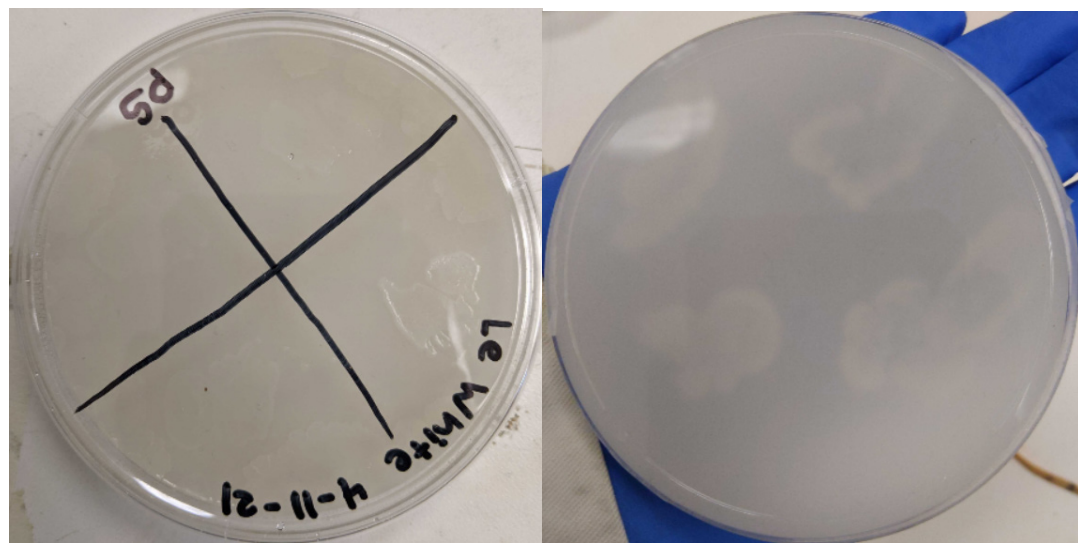

Figure B: The four colonies of the M. morganii strain and the four colonies of the B. cereus strain that were tested using the phosphate solubilization assay. The zones of inhibition were measured and recorded in Table B.

Table C: Data collected on the sizes of the zones of inhibition from colonies of the two species in the siderophore solubilization assay.

\begin{tabular}{|c|c|c|c|c|c|c|c|c|c|}
\hline \multicolumn{10}{|c|}{ Siderophore Solubilization Assay - Zone of Inhibition } \\
\hline \multirow{3}{*}{$\begin{array}{l}\text { Species } \\
\begin{array}{l}\text { Manii } \\
\text { gar- }\end{array}\end{array}$} & \multirow{2}{*}{$\begin{array}{l}\text { Colony } \\
\# 1\end{array}$} & \multicolumn{6}{|c|}{ Zone of Inhibition (mm) } & \multirow{2}{*}{$\begin{array}{l}\begin{array}{l}\text { Colony } \\
\text { Average }\end{array} \\
5.94 \mathrm{~mm}\end{array}$} & \multirow{3}{*}{$\begin{array}{l}\begin{array}{l}\text { Species } \\
\text { Average }\end{array} \\
5.72 \mathrm{~mm}\end{array}$} \\
\hline & & 14 & 10 & 4 & 1.5 & 0.2 & & & \\
\hline & $\# 2$ & 11 & 12.5 & 2.5 & 5.7 & 1 & 0.3 & $5.5 \mathrm{~mm}$ & \\
\hline \multirow{2}{*}{ B. cereus } & $\# 1$ & 3 & 4 & 2.5 & 3 & 2 & & $2.9 \mathrm{~mm}$ & \multirow{2}{*}{$2.62 \mathrm{~mm}$} \\
\hline & $\# 2$ & 2 & 3 & 2.5 & 2 & 2 & 2.5 & $2.33 \mathrm{~mm}$ & \\
\hline
\end{tabular}

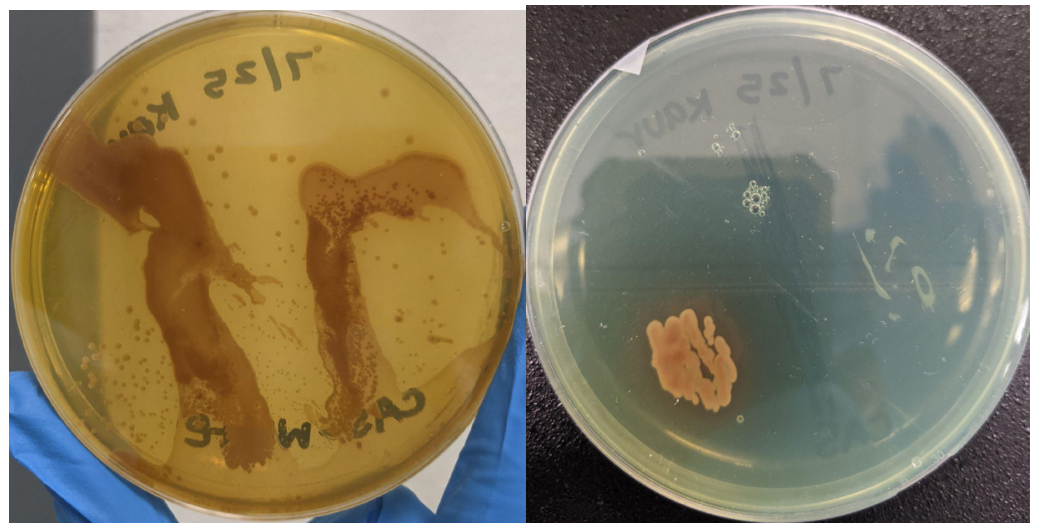

Figure C: The two colonies of the M. morganii strain and the two colonies of the B. cereus strain that were tested using the siderophore solubilization assay. The zones of inhibition were measured and recorded in Table $\mathrm{C}$. 
Table D: Data collected on the sizes of the zones of inhibition from colonies of the two species in the cellulase production assay.

\begin{tabular}{|c|c|c|c|c|c|c|c|c|}
\hline \multicolumn{9}{|c|}{ Cellulase Production Assay - Zone of Inhibition } \\
\hline Species & Colony & Zone & f Inh & ition & Im) & & Colony & Species \\
\hline \multirow{4}{*}{$\begin{array}{l}\text { M. mor- } \\
\text { ganii }\end{array}$} & \#1 & 5 & 2 & 3 & 4.5 & 2.5 & $3.4 \mathrm{~mm}$ & \multirow{4}{*}{$2.95 \mathrm{~mm}$} \\
\hline & \#2 & 2 & 4 & 3 & 2.5 & 1.5 & $2.6 \mathrm{~mm}$ & \\
\hline & \#3 & 4 & 3 & 4 & 2.5 & 2.5 & $3.2 \mathrm{~mm}$ & \\
\hline & \#4 & 2 & 2 & 1.5 & 5 & 2.5 & $2.6 \mathrm{~mm}$ & \\
\hline \multirow{4}{*}{ B. cereus } & $\# 1$ & 19 & 4 & 7 & 6 & 4.5 & $8.1 \mathrm{~mm}$ & \multirow{4}{*}{$8.575 \mathrm{~mm}$} \\
\hline & \#2 & 11 & 6.5 & 7 & 5.5 & 2 & $6.4 \mathrm{~mm}$ & \\
\hline & \#3 & 18.5 & 4.5 & 36 & 1 & 4 & $12.8 \mathrm{~mm}$ & \\
\hline & \#4 & 9.5 & 3.5 & 5 & 11 & 6 & $7 \mathrm{~mm}$ & \\
\hline
\end{tabular}

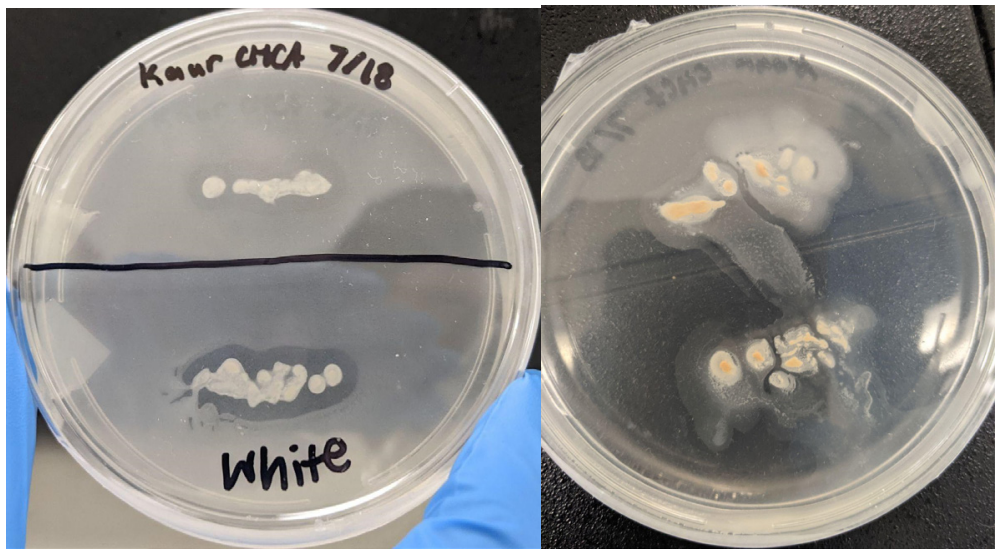

Figure D: The two colonies of the M. morganii strain and the two colonies of the B. cereus strain that were tested using the cellulase production assay. The zones of inhibition were measured and recorded in Table D. Note: A total of 8 colonies ( 4 for $M$. morganii and 4 for B. cereus) were tested using this assay, but only 4 colonies are included in this figure. However, data from all 8 colonies is included in Table D.

Table E: Data collected on the sizes of the zones of inhibition from colonies of the two species in the amylase production assay. 


\begin{tabular}{|c|c|c|c|c|c|c|c|c|c|}
\hline \multicolumn{10}{|c|}{ Amylase Production Assay - Zone of Inhibition } \\
\hline \multirow{3}{*}{$\begin{array}{l}\text { Species } \\
\begin{array}{l}\text { M. mor- } \\
\text { ganii }\end{array}\end{array}$} & \multirow{2}{*}{$\begin{array}{l}\text { Colony } \\
\text { \#1 }\end{array}$} & \multicolumn{6}{|c|}{ Zone of Inhibition (mm) } & \multirow{2}{*}{$\begin{array}{l}\begin{array}{l}\text { Colony } \\
\text { Average }\end{array} \\
2.42 \mathrm{~mm}\end{array}$} & \multirow{3}{*}{$\begin{array}{l}\text { Species } \\
\text { Average } \\
\\
2.792 \mathrm{~mm}\end{array}$} \\
\hline & & 2 & 4 & 3 & 2 & 2 & 1.5 & & \\
\hline & $\# 2$ & 5 & 4 & 3.5 & 3.5 & 1 & 2 & $3.17 \mathrm{~mm}$ & \\
\hline \multirow{2}{*}{ B. cereus } & \#1 & 3 & 4 & 3 & 1.5 & 5.5 & 3 & $3.33 \mathrm{~mm}$ & \multirow{2}{*}{$3.517 \mathrm{~mm}$} \\
\hline & \#2 & 2.5 & 0.7 & 2.5 & 6.5 & 7 & 3 & $3.7 \mathrm{~mm}$ & \\
\hline
\end{tabular}

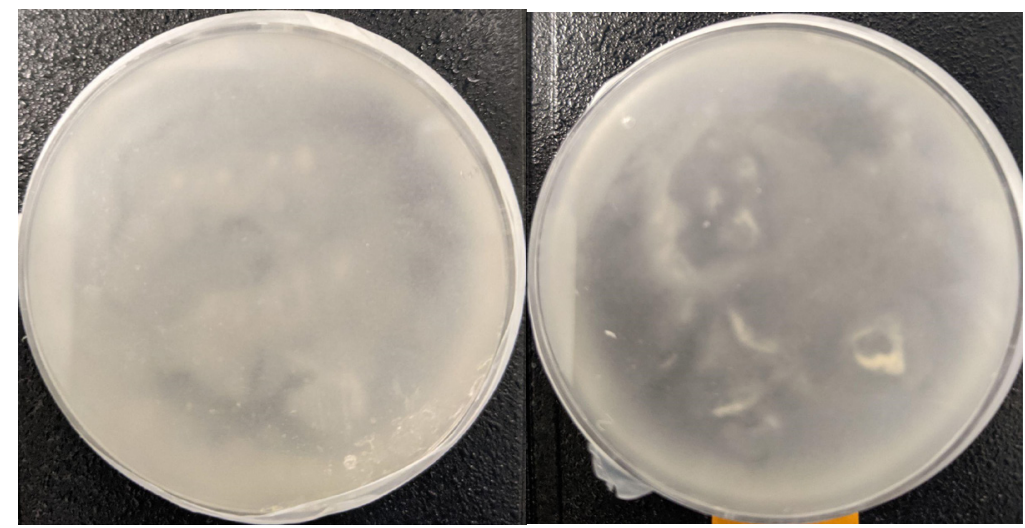

Figure E: The two colonies of the M. morganii strain and the two colonies of the B. cereus strain that were tested using the amylase production assay. The zones of inhibition were measured and recorded in Table E.

\section{Discussion}

This study was aimed to determine beneficial species of bacteria from a sample of soil collected from the LEAF community garden in Fremont.

The two groups of bacteria were identified as Bacillus cereus and Morganella morganii. ${ }^{16,17}$ To get here the bacteria were tested on a series of tests called assays which were explained above. These tests revealed properties of the bacteria which were useful to the soil and plants. Once these assays were done, the bacteria were put in a PCR machine and then sequenced for DNA. Once the results came back the DNA sequences were put into NCBI's BLAST nucleotide sequencer and then the species were identified.

A key part of the results for the assays were the zones of inhibition. Each assay tested the bacteria for a different compound. For the first assay of phosphate solubilization it tested for how well the bacteria could turn the phosphate compounds in the agar into a usable substance for plants. The zone of inhibition here tells us how well the bacteria used those compounds. So for the phosphate assay M. morganii performed pretty well on this test and it performed better than B. cereus. B. cereus had a zone of inhibition of $1 \mathrm{~cm}$ in diameter and $M$. morganii had a zone of inhibition $2-3 \mathrm{~cm}$ in diameter which indicates that $M$. morganii was better at processing the phosphate compounds. The second assay was cellulase production assay, which stands for carboxymethylcellulose, and this assay was used 
to test for how well the bacteria could use cellulose. B. cereus' zone of inhibition was 8.575 mm whereas $M$. morganii's zone of inhibition was $2.95 \mathrm{~mm}$, which tells us that $B$. cereus was much better than $M$. morganii at using cellulose. For the third assay, siderophore production, the bacteria were tested for how well they can use iron compounds. Here M. morganii performed much better than B. cereus. M. morganii had a zone of inhibition of $5.72 \mathrm{~mm}$ whereas B. cereus had a zone of inhibition of $2.62 \mathrm{~mm}$, which tells us that $M$. morganii can use iron compounds much better than $B$. cereus. The fourth assay is called amylase assay and this assay tests for how well the bacteria can use the enzyme amylase. For this assay B. cereus performed better than M. morganii. B. cereus had a zone of inhibition of $3.517 \mathrm{~mm}$ and $M$. morganii had a zone of inhibition of $2.792 \mathrm{~mm}$.

Each test completed on the bacterial species provided information on their characteristics. From these 4 of assays it was observed that the M. Morganii was better at using phosphate compounds and iron compounds. The compounds in those assays are in soil and usually without any change they can harm the plant. With these results it can be concluded that $M$. morganii probably helps a lot with breaking down these kinds of compounds in the soil. These compounds can then be used much more easily by the plants that need it. For B. cereus the assays show that this bacteria can use amylase and cellulase much better than $M$. morganii. This shows that $B$. cereus is much more effective at using enzymes than $M$. morganii, and $M$. morganii is better at using compounds than $B$. cereus.

Past experiments and research confirm our results and show that $M$. morganii and B. cereus are bacteria that perform well in soil. A paper by Pankaj Kumar et al. demonstrates that M. morganii removes lead, as well as many other types of compounds, really well. M. morganii essentially takes most chemicals that are noxious and turns them into less harmful chemicals. ${ }^{18}$ Another research article by Ann Sebastian et al. also discusses how B. cereus is a bacteria that usually is found around the roots of a plant. The study shows that $B$. cereus uses enzymes to help plant growth and these results corroborate with those of the present study. ${ }^{19}$

\section{Conclusion}

Soil from the LEAF community garden was taken and the bacteria from the soil was taken out and grown onto LB agar plates. The purpose of this study was to identify beneficial bacteria and to see how they can help plant growth. To test the efficacy of these bacteria, they were first put through a series of tests called assays to determine their properties, growth, and zone of inhibition to see how well they can help the plants. These assays had chemicals and enzymes found in plants that needed to be refined. Once these were finished the DNA was extracted and shipped off to a company for sequencing. After obtaining the results, the DNA sequences for each bacterial species were put through a BLAST from NCBI and the species of the bacteria was determined. Overall the results of the assays and names of the bacteria do corroborate with each other.

\section{Future Research}

Future research on this topic can be done to improve knowledge on these two bacterial species. Two examples of possible assays for future study are pectinase production, which breaks down the cell walls of fruits such as apples and oranges, and xylanase production, which breaks down hemicellulose, a major component of plant cell walls. The results of future biochemical assays in addition to those completed in this study will help increase our understanding of how M. morganii and B. cereus affect plant soil and plant growth.

Future applications for this research can be applied to areas for farming. These bacteria can increase the knowledge of soil for crop growth and can also help lessen crop failure. Additionally, these bacteria can improve the condition of the soil itself making it more fertile for the plants being grown. These applications can lead to more food production and lower chances of entire crops failing for a season.

\section{Acknowledgments}


We would like to express our appreciation for our fellow students Karan Saini, Ashneet Dhami, Angeline Ho, Maya Singla, and Riya Sanampudi for working with us in the beginning of our research. We would also like to thank the faculty of the Aspiring Scholars Directed Research Program for their guidance in the laboratory. We are especially grateful to our advisor Peter Le for assisting us in the initiation of this project, and to our second advisor Prabhjeet Kaur for helping us see it through to a successful outcome. Last but not least, we would like to express our extreme gratitude to the Olive Children Foundation and to the Aspiring Scholars Directed Research Program as a whole for providing us with this opportunity to explore the world of biological research.

\section{References}

1) Souza, Rocheli de et al. Plant growth-promoting bacteria as inoculants in agricultural soils. Genetics and molecular biology. vol. 38,4 (2015): 401-19. doi:10.1590/S1415-475738420150053

2) Kalayu, G. K. (2019, June 9). Phosphate Solubilizing Microorganisms: Promising Approach as Biofertilizers. Hindawi.

3) Phosphate solubilization and Siderophore production: A-the zone... (2017, September 26). ResearchGate. https:/www.researchgate.net/figure/Phosphate-solubilization-and-Siderophore-production-A-The-zone-ofinorganic-phosphate fig1 283649230

4) Eby Bassiri. (n.d.). Microbiology BIOL 275 DIAGNOSTIC TESTS FOR IDENTIFICATION OF BACTERIA. https://www.sas.upenn.edu/LabManuals/biol275/Table of Contents files/21-DiagnosticTests.pdf

5) Soil microbes could promote better farm outputs. (n.d.). ScienceDaily. Retrieved August 19, 2021, from https://www.sciencedaily.com/releases/2020/07/200720102052.htm

6) Jove.com. 2021. Bradley Schmitz and Luisa Ikner Culturing and Enumerating Bacteria from Soil Samples | Protocol. [online] Available at: <https:/www.jove.com/v/10099/culturing-and-enumerating-bacteria-fromsoil-samples $>$ [Accessed 28 August 2021].

7) Monteith, K. (2018, May 14). LB (luria-bertani) AGAR. protocols.io. https://www.protocols.io/view/lbluria-bertani-agar-p43dqyn.

8) Quick-DNA fungal/Bacterial Miniprep kit. (n.d.). ZYMO RESEARCH. https://www.zymoresearch.com/products/quick-dna-fungal-bacterial-miniprep-kit

9) Methods for microbial DNA extraction from soil for PCR amplification. (1998). PubMed Central (PMC). https://www.ncbi.nlm.nih.gov/pmc/articles/PMC140122/

10) Critical evaluation of two primers commonly used for amplification of bacterial $16 S$ rRNA genes. (n.d.). Applied and Environmental Microbiology. https://journals.asm.org/doi/10.1128/AEM.02272-07

11) Nucleotide BLAST: Search nucleotide databases using a nucleotide query. (n.d.). BLAST: Basic Local Alignment Search Tool. https://blast.ncbi.nlm.nih.gov/Blast.cgi?PROGRAM=blastn\&PAGE TYPE=BlastSearch\&BLAST SPEC $=\&$ LINK LOC=blasttab\&LAST PAGE=blastn

12) Pikovskayas Agar. HiMedia Laboratories Technical Data. (n.d.). Retrieved August 19, 2021, from https://us.vwr.com/assetsvc/asset/en US/id/8042423/contents

13) Arora, N. K., \& Verma, M. (2017). Modified microplate method for rapid and efficient estimation of siderophore produced by bacteria. 3 Biotech, 7(6). https://doi.org/10.1007/s13205-017-1008-y

14) Islam, F., \& Roy, N. (2018). Screening, purification and characterization of cellulase from cellulase producing bacteria in molasses. BMC Research Notes, 11(1). https://doi.org/10.1186/s13104-018-3558-4

15) Luang-In, V., Yotchaisarn, M., Saengha, W., Udomwong, P., Deeseenthum, S., \& Maneewan, K. (2019). Isolation and Identification of Amylase-producing Bacteria from Soil in Nasinuan Community Forest, Maha Sarakham, Thailand. Biomedical and Pharmacology Journal, 12(3), 1061-1068. https://biomedpharmajournal.org/vol12no3/isolation-and-identification-of-amylase-producing-bacteria-from-soil-in-nasinuancommunity-forest-maha-sarakham-thailand/ 
16) Kumar, P., Maurya, A., Garg, S., Yadav, A., Mishra, V., \& Sharma, R. S. (2020). Dead biomass of Morganella morganii acts as an efficient adsorbent to remove $\mathrm{Pb}(\mathrm{II})$ from aqueous solution in different aerationagitation and pH conditions. SN Applied Sciences, 2(7). https://doi.org/10.1007/s42452-020-3013-8

17) Sebastian, A. M., Umesh, M., Priyanka, K., \& Preethi, K. (2020). Isolation of Plant Growth-Promoting Bacillus cereus from Soil and Its Use as a Microbial Inoculant. Arabian Journal for Science and Engineering, 46(1), 151-161. https://doi.org/10.1007/s13369-020-04895-8

18) Dead biomass of Morganella morganii acts as an efficient adsorbent to remove Pb(II) from aqueous solution in different aeration-agitation and pH conditions. (2020, June 20). SN Applied Sciences. https://link.springer.com/article/10.1007/s42452-020-3013-8

19) Ann Mary Sebastian, Mridul Umesh, Kumaresan Priyanka, Kathirvel Preethi Isolation of plant growth-promoting bacillus cereus from soil and its use as a microbial Inoculant. (n.d.). Sci-Hub. https://scihubtw.hkvisa.net/10.1007/s13369-020-04895-8 